\title{
A Study of Hot and Cold Metaphors in Iraqi Arabic
}

\author{
Khalid Wahaab Jabber ${ }^{1}$ \& Hayder Tuama Jasim Al-Saedi ${ }^{2}$ \\ 1,2 Department of English, University of Misan, Iraq \\ khalid_jabber@yahoo.com
}

\begin{abstract}
Received : 2020-06-13
Revised : 2020-08-09

Accepted : 2020-08-09
\end{abstract}

ARTICLE HISTORY

\section{KEYWORDS}

Hot and cold

Metaphor

Conceptual Metaphor Theory

Dialect language

\begin{abstract}
The present study is an attempt to explore the ways of an Iraqi Arabic speaker conceptualises his/her understanding of various abstract domains of emotions or feeling and attitudes through his/her experiences of concrete domains of Cold and Hot metaphors. Lakoff \& Johnson's (1980) Conceptual Metaphor Theory is adopted to analyse the collected data. Idiomatic expressions and proverbs are chosen specifically from the southern dialect where they are widely used in daily interaction. The data analysis classified the results according to their abstract and concrete domains of the sampled data. The findings of this study showed different conceptualisations of the Hot and Cold metaphor in Iraqi Arabic. The study concluded that these metaphors are used to conceive more of the abstract concepts of emotions, feelings, and attitudes. Cold domain is used to conceptualise the bad habits of people, and it is also used to conceptualise some good habits, on the other hand. Whereas Hot domain is used to conceptualise the more intensive of emotions and attitudes. The study concluded that the sharp emotions, feelings and attitudes that are understood from the conceptualisation of Hot and Cold conceptual metaphors, are experienced from the more concrete domains of hard things.
\end{abstract}

\section{Introduction}

A speaker sometimes intends to use an expression figuratively when he/she feels that the literal use of language will not produce the intending effect. The figurative use of an expression, according to Croft \& Cruse (2004, p. 193) is attention-grabbing more than literal use. It might be the conveyance of new concepts or might conjure up a complex image that cannot be attained by any other way (Wisnita, 2019). The main kind of figurative usage is metaphor.

The English work 'metaphor' derives from the Greek word 'metaphora', in which 'meta' means 'to cross', and 'phor' is to 'carry.' The whole word means to transfer from one thing to another (Gao, 2016, p. 2630). Metaphor is a device that is omnipresent in everyday language (Derin et al., 2019). Lakoff \& Johnson (2003) indicated that it is not possible for us to live without metaphor because the ordinary conceptual system of humans is metaphorically structured (Zibin, 2016, p. 1). According to Ferrando (2017, p. 164) the pervasiveness of metaphor, nowadays, is widely accepted as a necessary cognitive mechanism in our conceptualisation of target domain. Metaphorical models, according to this view, provide coherence to many spheres of human culture, from law, politics, and economics, to religion, philosophy or science. Metaphor, according to Rasse et al. (2020), is a fundamental part of people's imagination and language.

In the perspective of cognitive linguistics, metaphor is the understanding of one conceptual domain in terms of another conceptual domain, as we understand life in terms of journeys and arguments in term of war (Landau, 2017, p. 62; Massey \& Ehrensberger-Dow, 2017, p. 174). Lakoff (2006, p. 186) defines metaphor as a cross domain mapping in the conceptual system. Whereas metaphorical expressions refer to a linguistic expression, such as word, phrase, or sentence, that is the surface realisation of such a cross mapping.

Moreover, in conceptual metaphor theory, the conceptual meaning construction is a matter of metaphors rising from correlation of experience (Kövecses, 2015, p. 1). According to Polova (2020, p. 407), a metaphor is an important means of preserving and transferring, stereotypes, associations, and standards and cultural achievements through generations.

Thus, metaphor and culture are connected together. The main point of metaphors is that we understand the world with it and not just speak with them (Lakoff \& Johnson, 1980). The shared understanding, as a large 
part of definition of culture, can often be metaphorical understood when the focus of understanding is on some intangible entities, such as our inner life, time, emotions, mental process, moral values, abstract qualities, and social and political institutions. The metaphors we use in these cases to understand these intangible may become crucially important in the way we actually experience the intangibles entities in a culture. Moreover, metaphors may be an inherent part of cultures (Kövecses, 2005, p. 2).

In Metaphor We Live By (1980: 282), Lakoff \& Johnson mentioned that there are three kinds of conceptual metaphors: structural metaphors, ontological metaphors and orientational metaphor. They treated them as having equal and independent status. According to Lakoff \& Johnson (1980) ontological metaphor refers to the device that treats the abstract and vague experiences. Such experiences are: events, feelings, actions, ideas, status and other intangible concepts as physical entity and material to make it easy to understand. Ontological metaphors are understanding the people experiences in terms of entities and substances which means that they can refer to them, quantify them, categorise them, and reason about them in ways otherwise impossible (Akuno et al., 2018, p. 42). Cold and Hot are one of the ontological metaphor as source domains by which we conceptualise many of our feelings or emotions, ideas, attitudes and events. Further, hot (heat) and cold are two basic human expressions. People feel warm and cold as a result of temperature of the air that surrounded them. The temperature domain is used metaphorically to express our attitude towards people and things, for example, a warm welcome and a cold reception. The source domain of heat (hot) is especially common in the metaphorical conceptualisation of desires and emotions, such as hate, love, rage... etc. A person can be described, for example, as 'burning with love' or 'smoldering with anger' (Kövecses, 2010, p. 20).

To be specific, one of the metaphors that has experiential basis in the functioning of the human body is ANGER IS HEAT metaphor. Metaphorical expressions that are instances of the ANGER IS HEAT metaphor can describe the heat of a hot fluid or that of fire in Iraqi Arabic like in English. Therefore, we have such words and phrases for anger as 'boil with angry,' 'make one's blood boil,' 'be seething'...etc. The ANGER IS HEAT is manifested from the experience that the angry person feels 'hot.' The experience of body heat is correlated with the experience of anger. This correlation serves the basis of the ANGER IS HEAT metaphor. Coldness is another emotional experience (Kövecses, 2010, p. 81; Kövecses et al., 2018, p. 4; Forceville, 2019). Coldness provides an experiential basis for the widespread of fear conceptualisation as being cold. This kind of fear conceptualisation can be seen in the expressions as ' $\mathrm{He}$ had cold feet to go inside.' Emotional experience is associated with the real change in the body temperature. This means that conceptual metaphor of fear is seen to be cold natural and experiential motivated.

Temperature in Iraqi community is come into contact with community habits, beliefs, desires, and even emotions and attitudes. Because the Iraqi weather is so harsh, this characteristic had a clear impact on the members of Iraqi community, one towards the others. Consequently, we find people describe their daily experiences in light of temperature whether it is warm or cold. The sharp emotions, desires and difficult attitudes are always conceptualised from the point of view of hot concepts, whereas they conceptualise bad emotions and attitudes in terms of cold concept and verse versa. By the same token, this pair of concrete domains is used to conceptualise the negative and positive abstract concepts using the idiomatic and proverbial metaphorical expressions. Metaphors are significant features of proverbs, which is why they have varied meaning. Proverbs, in fact, have been seen to be descriptions of a particular situation that can be applied to a wide range of situations (Ehineni, 2018, p. 131).

In this study, the researchers try to explore the way of Iraqi Arabic speaker to conceive his/her understanding of the abstract domains of emotions and attitudes...etc. that are realised from his/her experiences of the more concrete domains of Hot and Cold metaphors. In this study, the work is presented largely on the Lakoffian perspective of conceptual metaphor (Lakoff \& Johnson, 1980 and Lakoff, 1993).

\subsection{Conceptual Metaphor Theory}

Kövecses (2018, p. 124) mentioned that conceptual metaphor theory is a burgeoning field that dominates the study of metaphor. Its dominance is in large because of that conceptual metaphor theory made contact with a variety of disciplines and approaches in the study of human behaviour and human mind. The basic notion of Conceptual Metaphor Theory, which is a framework that was firstly proposed by George Lakoff \& Mark Johnson (1980), is that metaphor is not a stylistic feature of language but that thought itself is fundamentally metaphorical in nature. According to this view and to cross domain mapping, a conceptual structure is organised (Evans \& Green, 2006, p. 286; Kövecses, 2016, p. 31). In the same manner, Geeraerts $\&$ Cuyckens (2007, p. 190) suggested that mapping is the most fundamental idea of Conceptual Metaphor Theory. The term 'Mapping' borrowed from mathematics which refers to systematic metaphorical correspondences between the closely related ideas (Landau et al., 2018; Roodt, 2019, p. 4). 
In addition, Lakoff \& Johnson (1980) observed that metaphorical language is related to what is called the Metaphor System, by other means they noticed that the conceptual domain cannot be chosen randomly to describe the relationships between the domains. From this pattern, Lakoff \& Johnson hypothesises a conventional link at the conceptual level between the two domains. For example, LOVE IS JOURNEY is a conceptual metaphor where love is conceptually related to the domain of journey. In this view, love, the target domain, is conventionally structured in term of journey, the source domain. This operation, according to Lakoff and Johnson, is called Conceptual Metaphor (Evans \& Green, 2006, p. 294-295). Hence, asymmetrical directionality of conceptual metaphors is a feature most strongly emphasised by Lakoff and Johnson. 'Warm,' for example, is meaningful to refer to a person but meaningless to refer to a cup of tea as affectionate (Geeraerts \& Cuyckens, 2007, p. 191).

Furthermore, source domains, according to Lakoff and Johnson, are image schemas serve for the metaphorical mapping. Image schemas are knowledge structures emerge from pre-conceptual embodied experiences. Because knowledge structures of image schemas derived from the level of bodily experience, they are meaningful at the conceptual level. For example, counterforce image schema arises from the experience being unable to proceed because the attempt to move forward is being resisted by some opposing forces (Evans \& Green, 2006, p. 300-301; Kövecses, 2017, p. 7). Therefore, an image schema of 'Hot' and 'Cold' metaphors appears when one visualises or experiences the source domains of hot and cold in other abstract concepts, such as emotions, attitudes and events...etc. (Littlemore \& Taylor, 2014, p. 11).

Moreover, to understand the conceptual system and the corresponding between source and target domains, Lakoff (2006, p. 190) proposed a metaphorical scenario as a system. He suggested that a metaphor includes understanding one domain of experience (for example, love) in terms of a very different domain of experiences (for example, journeys). In more technical way, the metaphor can be understood as mapping from a source domain (journey) to a target domain (love). In conceptual metaphor LOVE IS JOURNEY, there is what Croft \& Cruse (2004, p. 196) and Kövecses (2015: 2-3) called 'ontological corresponding' between source and target domain, the entities of domain of a love (the lovers, the common goals, difficulties, the love relationship, etc.), correspond systematically to the entities of the domain of a journey (the travellers, the vehicle, destinations, etc.). There is another sort of mapping of domains, Lakoff called it 'epistemic'. Epistemic mappings correspond between elements in one domain and relations between elements in other domain. Lakoff \& Johnson (1980), Lakoff (1993, p. 41), as well as Croft \& Cruse (2004, p. 196) adopted a mnemonic strategy for naming the mappings in conceptual metaphor. This strategy has a form of TARGET-DOMAIN IS SOURCE-DOMAIN, or alternatively TARGET- DOMAIN AS SOURCEDOMAIN.

Additionally, to distinguish between concrete domain and abstract domain, Lakoff \& Turner (1989, p. 94) and Clausner \& Croft (1999, p. 14) give a clear idea about these two concepts. They state that concrete domains are mental representations, also they are representations of embodied experiences. These embodied experiences can be represented as images. Abstract domain, on the other hand, cannot be represented as images and they do not have the kind of experiential of grounding (Kövecses, 2017; Roodt, 2019; p. 3).

Just as important as a metaphorical interaction between anger and heat or fire for Arabic language as with English, in the mapping, the abstract domain of anger is conceptualised through the concrete domain of fire or hot. In Anger is hot or fire metaphor, the conceptualisation process depends on a set of mappings or systematic correspondences that exist between anger and fire.

\subsection{Hot and Cold Metaphors in Iraqi Arabic}

Iraqi Arabic speakers are always used figurative language and thought to express their daily social and cultural experiences. Because of the social and cultural relationships that correlate the entities of Iraqi community and the community is organised as trips and big families, idiomatic and proverbial expressions play an essential role in determining the way an Iraqi speaker deals with others. Accordingly, idiomatic expressions and proverbs, as an ancient folklore, not so long ago, are experienced from ancestors to the children in conceptualizing social and cultural abstract concepts of emotions and attitudes...etc. by many of Iraqi speakers in terms of concretes domains of Hot and Cold. Hot and Cold are two conceptualised metaphors that are commonly used to conceptualise a wide range of abstract domains negatively and positively.

\section{Method}

In this study, the researchers try to explore the way speakers in Iraqi community conceptualise the abstract domains of emotions and attitudes...etc. that are realised from their experiences of the more concrete concepts of Hot and Cold metaphors. This study adopted the Conceptual Metaphor Theory (Lakoff \& Johnson, 1980; Lakoff, 1993) to analyse the collected data. 
Some idiomatic and proverbial metaphorical expressions are gathered from the Iraqi community specifically the southern community dialect where such idiomatic and proverbial metaphorical expressions are largely used.

For data analysis procedures, firstly, the data are translated into English and then an Arab phonetic transcription are adopted in order to be cleared to the Arabic readers. Secondly, the research data are classified into conceptual metaphors according to their metaphorical corresponding. Thirdly, the researchers begin their analysis with explaining the traditional, cultural and lexical dimensions of the data and then investigating how the speakers use these proverbs and idiomatic expressions to understand more of abstract concepts in their daily interaction by showing the set of relations between metaphorical expressions and conceptual metaphors. Fourthly, a figure is drawn after each point of conceptual metaphors to illustrate to components of metaphorical mapping: source concept, target concept, mapping and mapping scope.

\section{Findings}

This part deals with analysis of expressions and proverbs depending on Lakoff \& Johnson (1980) and Lakoff (1993) perspectives on Conceptual Metaphor Theory. Twenty-five conceptual metaphors are arranged as points to be analysed one by one.

\subsection{Idiocy and Neglegence are Cold}

When someone is idiot, people describe him by saying this idiomatic expression 'Colder than Saqa back' /ābrd mn tyz ālsqh/. Literally, 'Saqa' /sqh/ is a lexical item refers to the bottom of a traditional thing, a water container, which was using to transfer and buy a cool water in popular neighbourhoods. Thus, the coldest part of the 'Saqa'/sqh/ is the bottom where water is settled in.

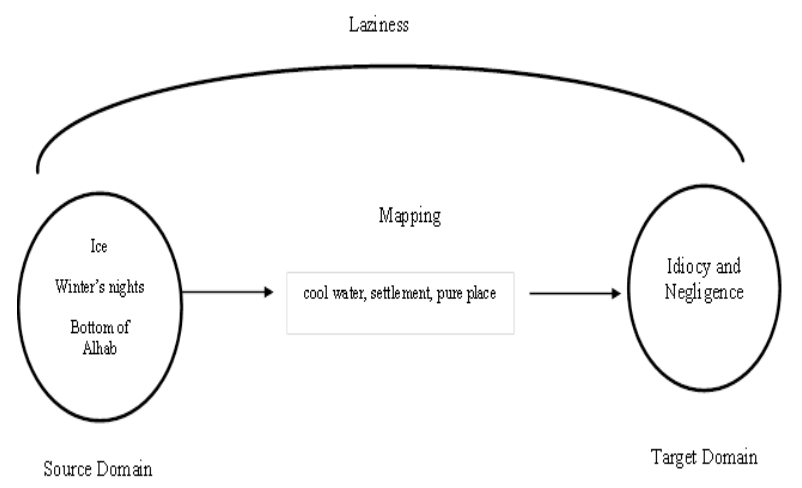

Figure 3.1 Image Schema of the Proverb "Colder than Saqa Back."
In Iraqi Arabic situation, psychologically, the lexical item ' $\mathrm{Saqa}$ ' $/ \mathrm{sqh} /$ is related to a person who has a characteristic of being an idiot, absent or marked deficiency of intelligence. Iraq Arabic speaker always uses an idiomatic expression 'Colder than Saqa's back' /ābrd mn tyz ālsqh/ to conceptualise his understanding of the abstract domain of idiocy by linking it to the more concrete domain of cold through a set of metaphorical mapping that correspond the entities of 'Saqa back' /tyz âlsqh/ of cooling in relation to entities of an idiot person.

Another idiomatic expression that it used to refer to the idiot person is 'Colder than ice' /ābrd mn ât 1 ' 1 ğ $/$. Because 'ice' is an indication to low temperature of cold where the entity of 'ice' being inflexible thing corresponds to the emotional entities of idiot person who does not have vitality or he/she is abnormal person (Kövecses, 2000; Kövecses, 2005; Kövecses, 2010).

The abstract domain of idiocy of a person is conceptualised onto mapping of the concrete domain of inflexibility of ice. In the same way, he/she conceptualises his/her experience of concrete domain of cold by using the proverb 'Colder than winter's nights' /ābrd mn lyāāly ālšst'/, where 'winter's nights' /lyāāly àlšt'/ have a feature of low temperature on which a person has a little movement and physically be less vitality. Therefore, an Iraqi speaker understands the target concept domain of idiocy from his experience of low temperatures of winter's night.

Furthermore, there is another proverb that is used to express that someone is idiot or neglected, 'Colder than the bottom of "Alhab"' /ābrd mn ğ 'b älhb/ 'Alhab,' a folklore thing or object, is used by most of Iraqi's families to cool and purify water, it is made by pottery which has a property to make water cold. Bottom is the colder place of 'Alhab' /āl ḷb/.

The water in it is stagnate and cold. Consequently, an Iraqi speaker experiences his attitude towards a neglected person, who is not proficient in his work, from that colder place. Thus, a target domain of negligence is conceptualised onto mapping of more concrete domain of colder bottom of 'Alhab' /ālhb/.

\subsection{Resolving is Cold}

When someone is exposed to a problem or he/she faces a trouble and this problem is almost done, others would describe this case as 'cooled down'. The Iraqi speaker expresses this situation in which a trouble is solved as 'The issue is cooled' / brdt ālqḍh/. 


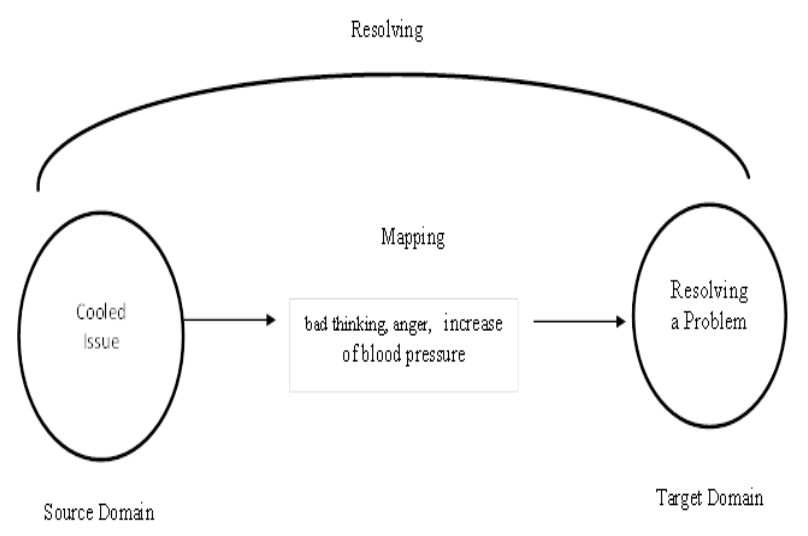

Figure 3.2 Image Schema of the Proverb "Problem is Cooled."

The concept of a problem is related psychologically to decrease the emotional anger and bad thinking, and physiologically to the decrease of blood pressure as a reaction to a problem occurred. Hence, the physiological entities of cold domain correspond systematically to the psychological and physiological issues to a person who exposed to a problem (Kövecses, 2000; Kövecses, 2005; Kövecses, 2010). He then, conceptualises the abstract domain of solving a problem in term, of more concrete domain of cold which has a feature of decrease of temperature.

\subsection{Vitality is Hot}

When someone is eager to achieve his duties, others describe him by using the idiomatic expression 'Hotter than the lover's heart' / āḥr mn klb āl'āšk/. The phrase 'lover's heart' /klb āl'āšk/ refers to a person who has a high enthusiasm and energy.

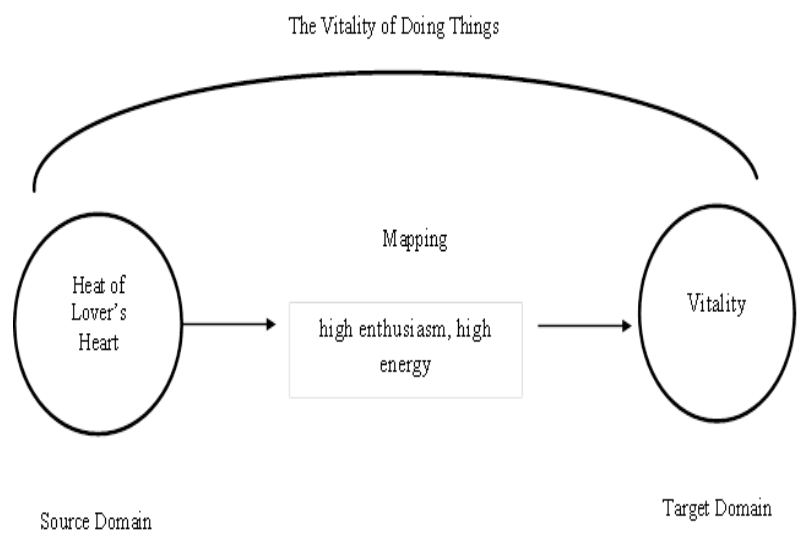

Figure 3.3 Image Schema of the Proverb "Hotter than the Lover's Heart."
Lover's heart characterises with heat that denote the case of beloved belonging to his/her lover. The emotions of love in the lover's heart correspond to a set of entities of a person who has vitality of doing things (Kövecses, 2000; Kövecses, 2005; Kövecses, 2010). A lover is always eager to see his beloved and do anything he/she wants, because of this, a lover is always having a vital to be expressed as high enthusiasm and energy. Therefore, a target domain of vitality is conceptualised onto mapping of a set of corresponding structures of more concrete domain of heat found in lover's heart.

\subsection{Composure is Cold}

The Iraqi Arabic idiomatic expression 'His blood is cold' / $\mathrm{dmh} \mathrm{bard} /$ is used to express that someone is very quiet.

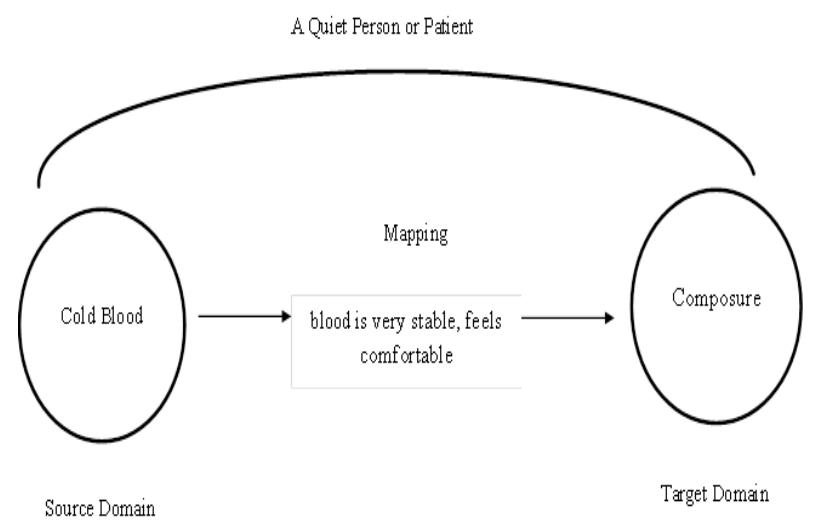

Figure 3.4 Image Schema of the Proverb "Blood is Cold."

The lexical item 'cold' traditionally linked with an Iraqi culture to refer to a person who is so patient or quiet. Physiologically, a person's blood, when he/she is quiet or patient, becomes very stable and he feels comfortable. The structure of blood when the person was quiet corresponds to the characteristic of composure (Kövecses, 2000; Kövecses, 2005; Kövecses, 2010). Therefore, a speaker conceptualises his feeling of abstract concept of composure onto mapping of the concrete domain of blood.

\subsection{Opportunity is Hot}

When someone takes the advantage of opportunities or achieves something in an appropriate time, this case is described by expressing the idiomatic expression 'As the iron is hot' /mādāmt ālḥdydh hạārh/. The noun phrase 'iron is hot' /ālhịdydh hāāh/ is concerned with the fact that when the metals especially iron become hot, it is easy to change its shape. 


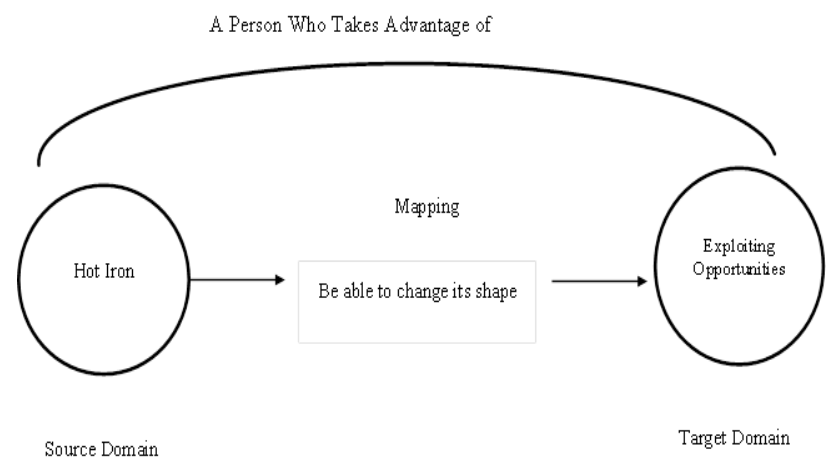

Figure 3.5 Image Schema of the Proverb "Iron is Hot."

The entities of hot iron being able to change its shape correspond to the characteristics of a person who is able to exploit the chances. Therefore, the best chance to change the shape of the iron material is when it becomes so hot. Henceforth, a speaker conceptualises his/her understanding of abstract domain of exploiting the opportunities by linking it to the more concrete domain of hitting hot iron.

\subsection{Waiting is Hot}

When someone is waiting another for long time, speakers describe this waiting situation by experiencing the idiomatic expression 'Hotter than cinder' /āḥr mn àlğmr/. Because waiting is an innate emotion mostly interrelated with the psychological mechanism (Kövecses, 2000; Kövecses, 2005; Kövecses, 2010).

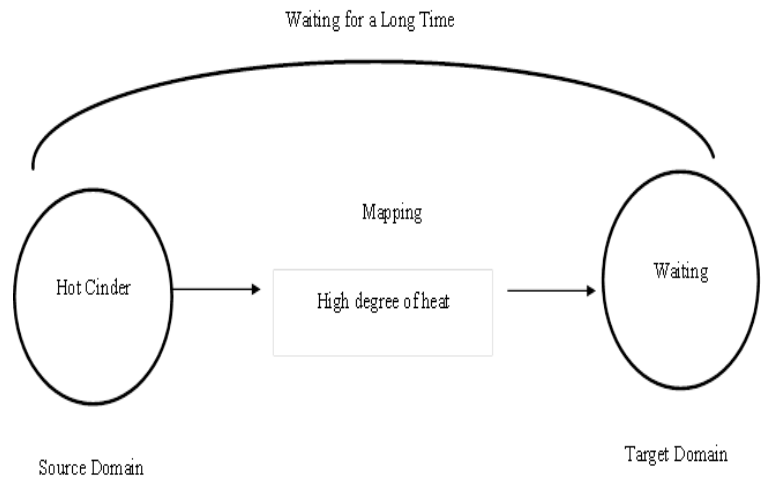

Figure 3.6 Image Schema of the Proverb "Hotter than Cinder."

For this reason, most of Iraqi speakers understand the concept of waiting by comparing it with lexical item 'cinder' /ālğmr/. The lexical item 'cinder' /ālğmr/ has a property of high degree of heat. Therefore, the speaker's psychological mechanism of waiting corresponds systematically with the high degree of heat. Thus, the concrete domain ' $h o t$ ' is used metaphorically to express the abstract psychological emotions of 'waiting.'

\subsection{Cheating is Cold}

When someone is deceiving the others, speakers describe this behavior by experiencing the proverb 'Buys ice from us and sells cold water on us' / yštry mn 'dnh tllğ wyby'lnnh māy bard/.

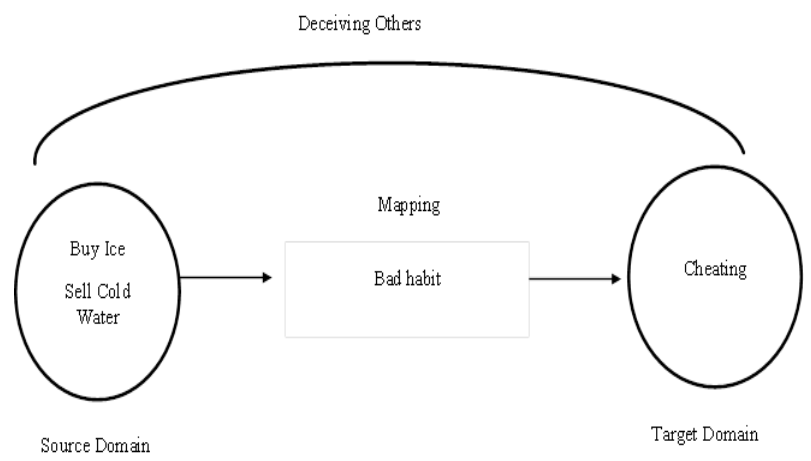

Figure 3.7 Image Schema of the Proverb "Buy Ice and Sell Cold Water."

In this proverb, a cheating behaviour is described by buying something different from the actual thing the seller wants to sell. The two unrelated materials 'ice' and 'cold water' show the speaker's experiences of the bad habit of cheating. 'Ice' for speakers is precious material whereas 'cold water' is cheaper than that. This contradiction of exchanging materials by the speaker lead to conceptualise his understanding of the abstract domain of cheating through a set of corresponding mapping of concrete domain of buying ice and selling cold water.

\subsection{Health is Cold and Hot}

Health, in Iraqi community, is also related traditionally to the culture of people and their experiences with body health. When someone has an accident or problem and others want him not to be affected, they express their thought by using the proverb 'Warm your head and cool your legs' /dfy rāsk wbrd rğlyk/.

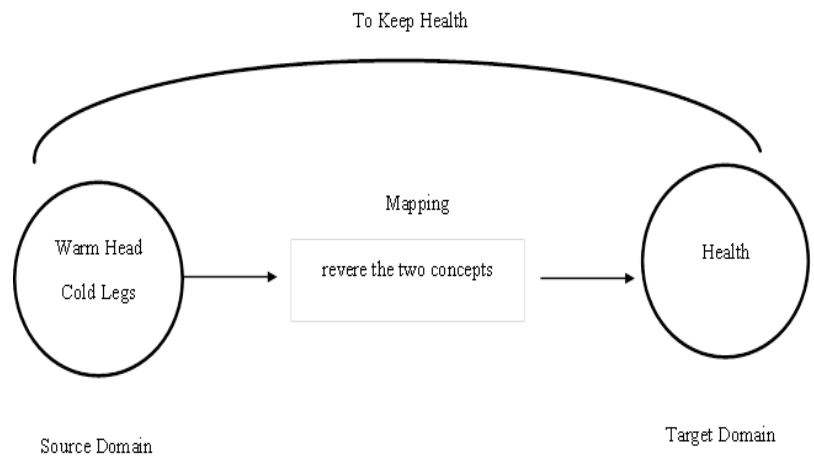

Figure 3.8 Image Schema of the Proverb "Warm Your Head and Cool Your Legs." 
According to speaker's experiences, two unrelated things that a human being should be done to be in good health; the first is 'warm head' and another is 'cold legs.' Thus, a speaker reveres the two concepts as an indication to someone, who had an accident, to keep his health and be alive. Hence, a speaker conceptualises his understanding of a body to be healthy in terms of mapping of more concrete domains of warming a head and cooling legs.

\subsection{Satisfaction is Cold}

The expression 'Cold water pours on the heart' /māy bārd ynzl ' $1 \mathrm{klb} /$ is used metaphorically to refer to someone who is satisfied about someone or doing something.

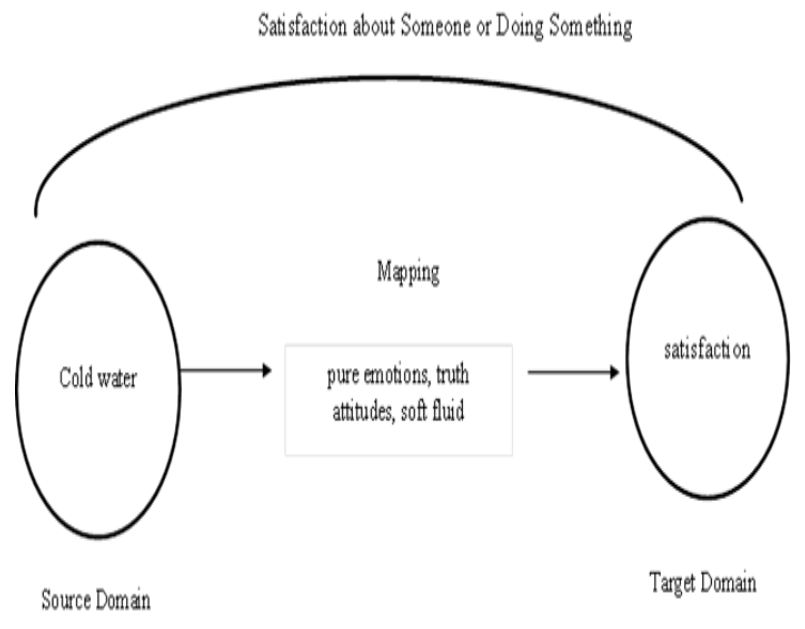

Figure 3.9 Image Schema of the Proverb "Cold Water Pours on the Heart."

Water, in Iraqi community, is a fluid used always to express pure emotions and real attitudes. When someone is satisfied, a speaker expresses metaphorically that a water is pours on the heart, because heart is the container of satisfaction. The structures of water being cold, pure and soft correspond the feature of an abstract notion of satisfaction. In this case, a speaker conceptualises his/her feeling of satisfaction in terms of a set of mapping onto a concrete domain of a cold water which pours on the heart.

\subsection{Treason Someone and Gaining Something are Cold}

The proverb 'Ate it cooled and be cooled' / āklh bārdh mbrdh/ is used metaphorically to express that someone is exposed to treason in a way that another follows smart tricks to do that.

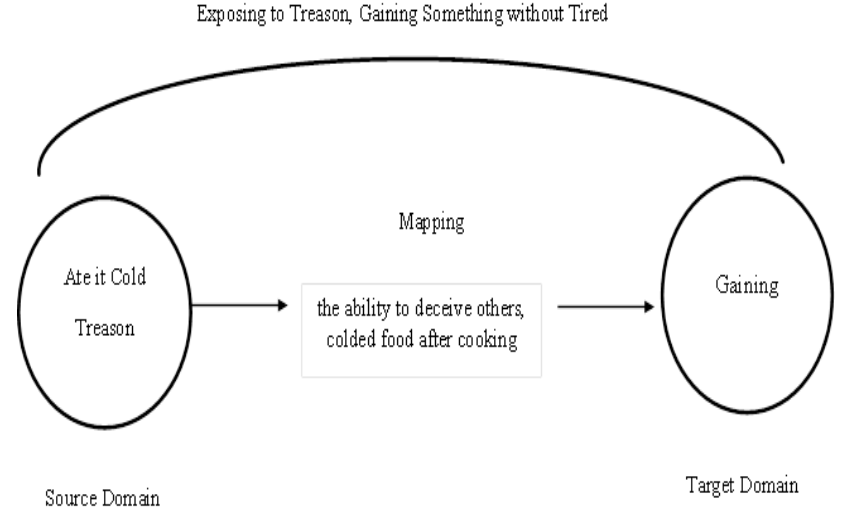

Figure 3.10 Image Schema of the Proverb "Ate It Cooled and be Cooled."

The lexical item 'cold' /bard/, in Iraqi culture, comes into contact with a habit of a person who has the ability to deceive and betray others. The image schema of 'cold' emerges from the bodily pre-experience of property of doing something intending to treason others. In this proverb, a speaker conceptualises his abstract domain of feeling treason onto a set of mapping of concrete domain of eating something cooled.Sometimes, this proverb is used to express that person achieves something without being tired or discomfort. The phrase 'ate it' refers that a person who gets something without doing an effort or trouble because the lexical item 'cooled' $/ \mathrm{mbrdh} /$ refers to a food after cooking where a person tries to be make it to be suitable for eating. The experience of cooled eating corresponds to the entities of gaining something without efforts. In this situation, a speaker conceptualises his understanding of gaining something without effort onto a set of corresponding of eating something cooled.

\subsection{Underestimating Grace is Cold}

The proverb 'The taste in the hot and the blessing in the cold' /āldh bālḥār wālbrkh bālbārd/ is used to express the case of someone who has great fortune.

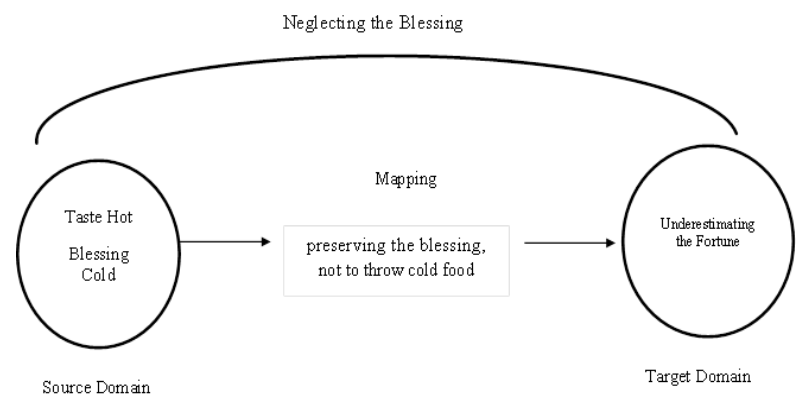

Figure 3.11 Image Schema of the Proverb "The Taste is in the Hot and the Blessing is in the Cold." 
When a person does not know how to deal with his fortune, others describe this behaviour by telling him that the blessing in cold food as far as the taste is in the hot food and this behaviour regarded as neglecting the blessing.

Therefore, to keep your possessions you have to keep it from loss. Thus, a speaker is advised not to throw cold food because he could make it hot. The entities of cold food correspond systematically to the thought of preserving the blessing. A speaker, then, conceptualises his/her understanding of abstract domain of underestimating the fortune or grace by linking it to the more concrete of warming food even it was cold.

\subsection{Calmness is Cold}

The idiomatic expression 'Hit a cold to him'/țklh $\mathrm{bard} /$ is used to express the reaction of someone who is nervous.

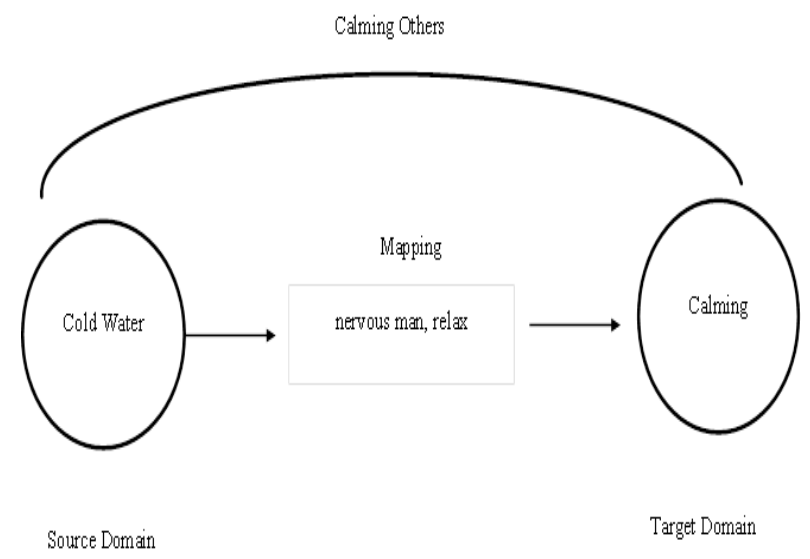

Figure 3.12 Image Schema of the Proverb "Hit a Cold."

The image schema of cold drink arises from a speaker's experiences of the physiological thought that a cold drink make a nervous man relax. As a consequence, the expression 'Hit a cold to him'/țklh bard/, in Iraqi culture, has features of calming others. The structure of concrete domain of 'cold drink' corresponds systematically to the entities of making someone relax. Hence, in conceptual metaphor CALMNESS IS COLD, a speaker conceptualises his/her feelings of calming as a target domain through a set of mapping of concrete domain of lit someone a cold drink.

\subsection{Changing Facts is Cold and Hot}

When a person behaves according to his/her willing not his mind, others describe him/her using this proverb 'when he wants it hot, it is hot and when he wants it cold, it is cold' /mn yrdh hāāh hạārh wmn yrydh bārdh bārdh/.

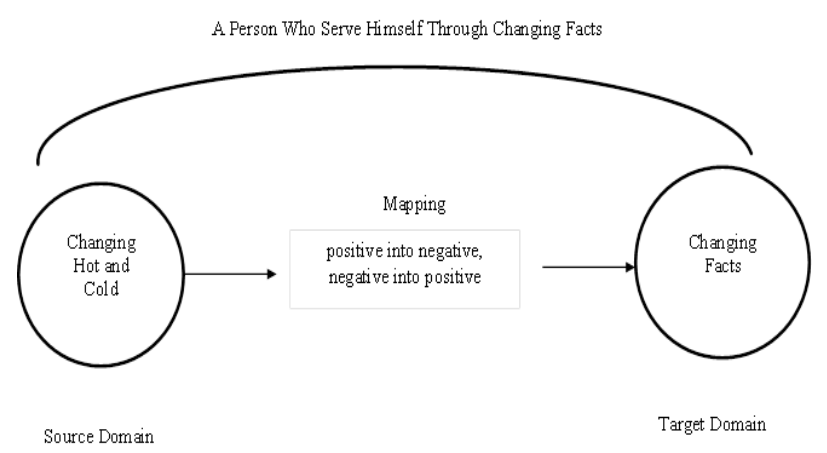

Figure 3.13 Image Schema of the Proverb "Hot When You Want Hot, Cold When You Want Cold."

This proverb is used to express a person who has the ability to change facts and consecrates them to serve himself. The lexical item ' $h o t$ ' /hâar/ belongs to himself being positive fact whereas the lexical item 'cold' is negative fact is used against others. Thus, a speaker conceptualises his/her feeling towards a person who changes facts onto mapping of concrete domains of hot and cold to be changed according to the person's opinion.

\subsection{Hesitation is Hot}

The proverb 'hot in hot' /hāar bḥār/ is used to express that someone not to be hesitated to do something. The vitality of doing something comes from the idea of achieving something when it is ready, it may be come from the food because human beings prefer to eat when it is hot or shape things from iron metal when it is hot.

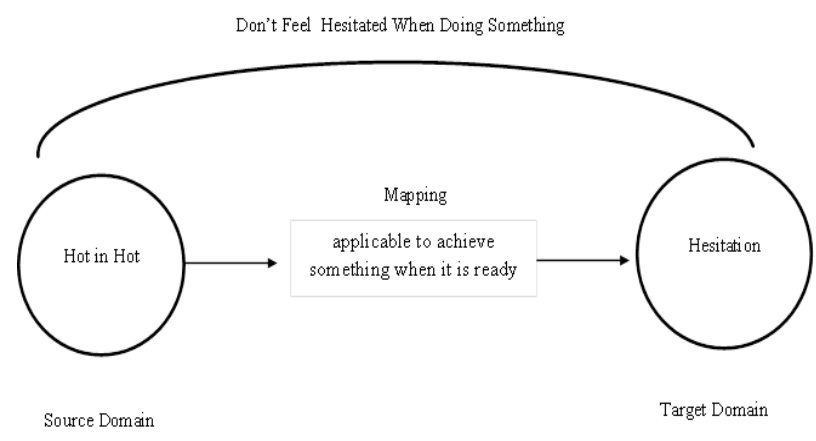

Figure 3.14 Image Schema of the Proverb "Hot in Hot."

This proverb enhances people to do things without hesitation and thinking. Thus, an image schema of hot domain arises from speaker's experience of being applicable to achieve something when it is ready. The entities of hot things when it is hot correspond to entities of a person's behaviour towards the attitudes he exposed to. For this reason, a target domain of a speaker's hesitation or not is conceptualised through a set of mapping of concrete domain of a hot thing is being hot. 


\subsection{Sacrifice is Hot}

When someone is eager to help others, this humanity characteristic, that an Iraqi speaker is characterised with, is expressed by metaphorical expression 'burned his blood on them' /hārk dmh 'lyhm/. The entities of domain 'burn' /yhrrk/ such as (damage, disappearance, heat...etc.) correspond systematically to the entities of domain sacrifice, such as (lose time, being tired, embarrassment...etc.).

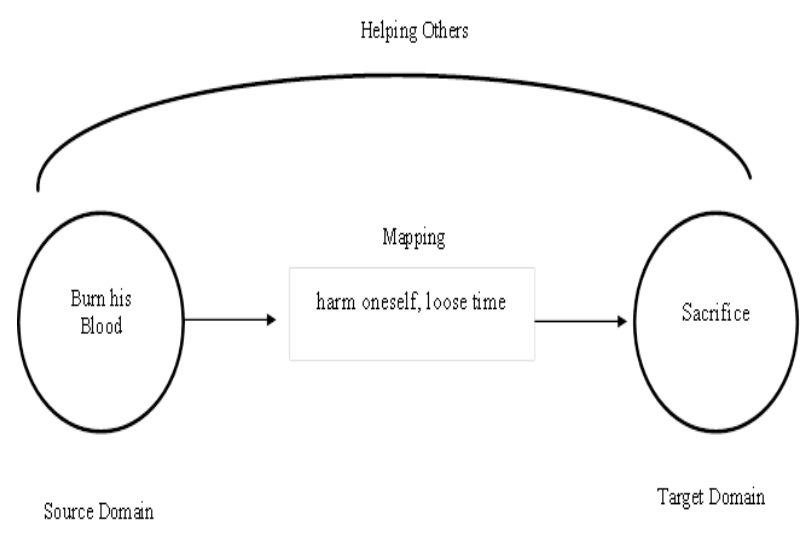

Figure 3.15 Image Schema of the Proverb "Burned His Blood"

Thus, the knowledge of image schema of source domain appears when someone's bodily experiences of hot metaphor being harmful for himself to help others. Under those circumstances, conceptual metaphor of SACRIFICE IS HOT is understood as the target domain of sacrifice onto mapping of the more concrete domain of burning blood to help others.

\subsection{Anger is Hot}

When someone feels angry, Iraqi Arabic speakers describe him/her by an expression 'This is hot pepper' / hd̄a flfl hāar/. One of the pepper qualities is spicy, but we use hot literally to mean spicy figuratively. Traditionally, there is a relation between a hot in pepper and anger, because anger causes increase in a human heat and blood.

Therefore, a person who becomes anger, an Iraqi people describes his/her blood being hot as in the expression 'His blood is hot' /dmh hārr/. There is a relation between the domain 'pepper' /flfl/ being an entity of high degree of heat and a target domain of anger which has a property of feeling nervous. In the same way, the relation between the domain 'blood' which it has a property of high pressure. Therefore, Iraqi speaker conceptualises his/her feeling of anger through his/her knowledge and experience of concrete domains of 'pepper' /flfl/ and 'blood' being hot through a set of corresponding mapping mentioned above.

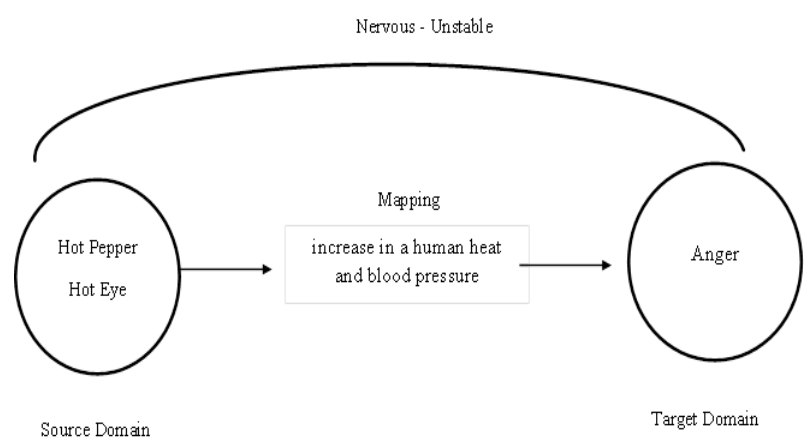

Figure 3.16 Image Schema of the Proverb "Hot Pepper" and "Hot Eye."

Another expression that is used to express anger is 'His eye is hotter than embers' /'ynh āḥr mn ālğmr/. According to the biological case of human body, anger appears in a person's eye as unconscious feeling. Hence, most of Iraqi speakers refers to the anger as 'hotter than embers' /āḥr mn ālğmr/, because embers have a high quality of heat, a speaker conceptualises his/her understanding of it from being linked to the more concrete knowledge of the properties of hot domain that appeared in his eyes.

\subsection{Luck is Hot}

Luck is expressed by the traditional saying 'If your market was hot, boil dogs and sell' / ādāa ğān swkk hāar āslk ğlāb wbt \% Dogs, for Iraqi people, are prevented from eating, so when you are lucky you can sell even dogs.

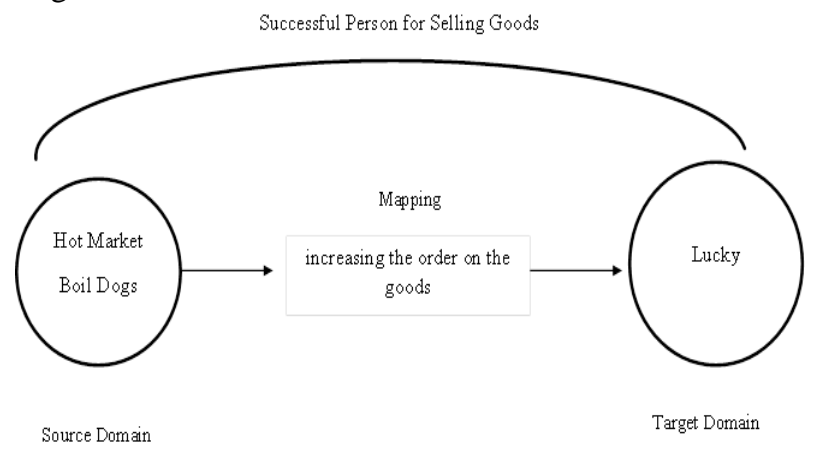

Figure 3.17 Image Schema of the Proverb "If the Market is Hot, Boil Dogs and Sell."

Increasing order on goods in the markets is expressed by the sellers as hot. The expression 'Market is hot' /swkk hār/ has features of increasing of buying goods which identical to the characteristic of a lucky person who has an ability to be a successful seller even buying cooked dogs. This expression is used to conceptualize the abstract feeling of a person who is lucky in obtaining what he wants to do by liking it to concrete domain of buying goods even cooking dogs for buying. 


\subsection{Death is Hot}

When a person becomes old, he/she loves to live for a long time. Iraqi Arabic speakers utilise the proverb 'The soul is precious and the grave is hot' /ālrwh 'zyzh wālkbr hạ̄r/ to express that the life of someone is near ended.

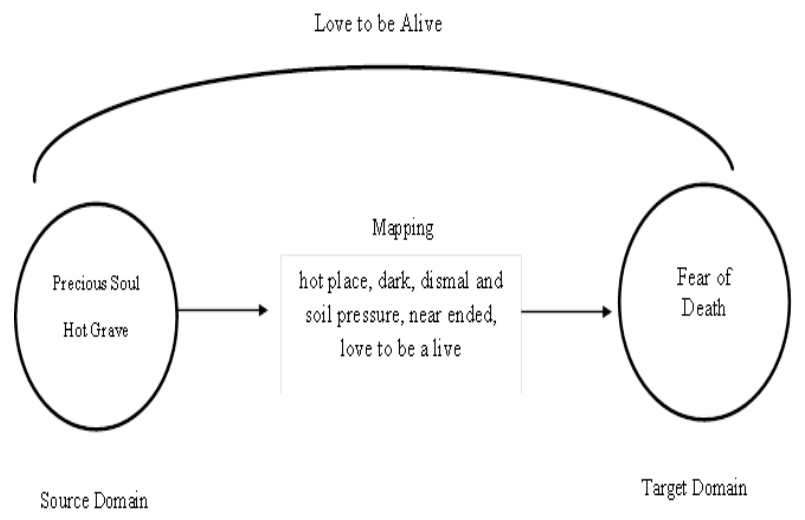

Figure 3.18 Image Schema of the Proverb "The Grave is Hot."

Traditional thought for grave, as a container, is a hot place, dark, dismal and soil pressure. These experiences knowledge of grave, as an image schema, are corresponded to the features of the idea of a person, when the live in near ended, loves to be alive and afraid of sick...etc. Thus, a speaker conceptualises the abstract domain of survival feeling and the fear of death in term of concrete domain of the entities of a grave being hot, dark...etc.

\subsection{Carelessness is Cold}

The Iraqi Arabic proverb 'What is hottest in me, is coldest in him' /āḥr mā 'ndy āābrd mā 'ndh/ is used to express an event when someone cares of another person's feeling, but he/she gets faced nothing from him.

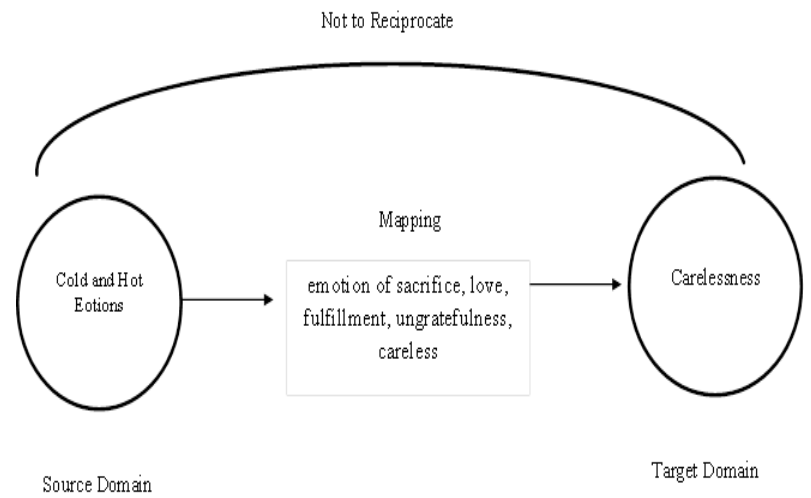

Figure 3.19 Image Schema of the Proverb "Hottest in Me, Coldest in Him."
The two expressions serve a relation of two contradictory emotions, the expression 'what is hottest in me' /āhr mā 'ndy/ has an emotion of sacrifice, love, fulfillment whereas the feeling of 'coldest in him' /āābrd mā 'ndh/ expression is ungratefulness, careless. Therefore, the image schema appeared from the speaker's emotions experiences of hot being positive behavior towards another person even if he showed negative emotions. Thus, a speaker, by uttering this proverb, conceptualises his/her comprehension the abstract domain of bad feeling as carelessness by linking it to concrete domain of ungratefulness emotions and cold.

\subsection{The Cuckold Man is Cold}

A person who has no emotion of sexual prowess on his wife or daughter, others describe him/her by saying the idiomatic expression 'Colder than pig blood' /ābrd mn dm ālhnzyr/.

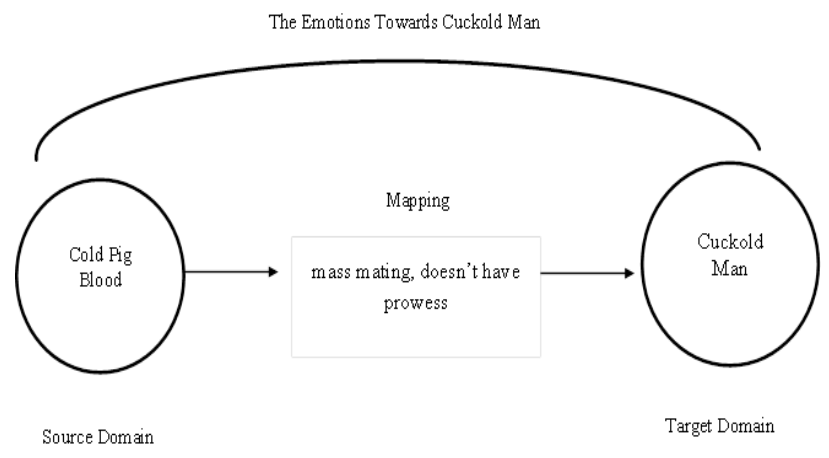

Figure 3.20 Image Schema of the Proverb "Colder than Pig Blood."

Traditionally, pig is characterised as cuckold because this animal has an ability to mass mating even with its mother. The knowledge of source domain is emerged from pre-conceptual embodied experiences of pig animal which hasn't sexual prowess towards his family group. Thus, the emotions entities in pig is related consciously to the entities of a person who disaffected of others who having sexual relationship with his daughter or wife. As a result, an Iraqi speaker understands his emotions of the target domain of cuckold through conceptualizing the concrete domain of pig blood being colder than it.

\subsection{Good Morals is Hot}

This proverb 'Clearer than tear and hotter than candle' /āṣf' mn āldm 'h wāḥr mn ālšm ' $\mathrm{h} /$ is described to someone who is characterised by loving others and has good manners. Physically, a human eyes' tears are very clear. 'Candle'/ālšm ' $\mathrm{h} /$, on the other hand, when it burns, emits from it an extreme heat that burns human fingers. 


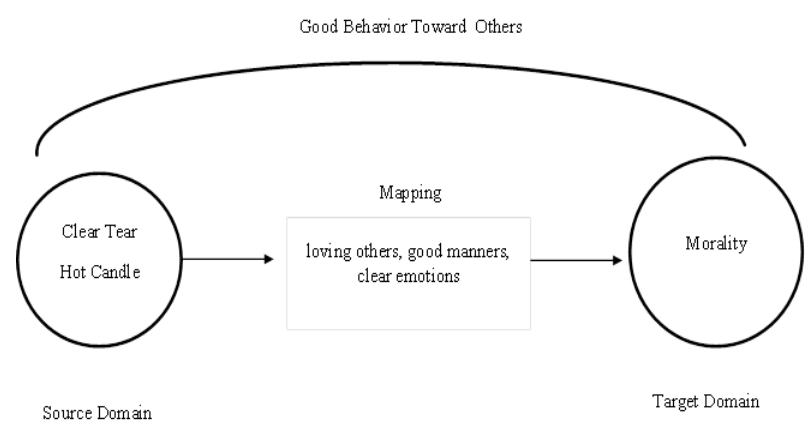

Figure 3.21 Image Schema of the Proverb "Clearer than Tear and Hotter than Candle."

In this case, a speaker knowledge appeared from pre-conceptual experiences of a set of correspondence mappings between the entities of tears' clear and candle's heat and the emotions of a human being who having good moral habit of behavior. Accordingly, an Iraqi speaker conceptualises the features of tear's clear and candle's heat as concrete domains to understand the abstract domain of human beings' emotions of morality.

\subsection{Hospitality is Hot}

One of the best habits that Iraqi people familiar with is serving food for a guest, is called hospitality. When someone hosts a friend, the food should be hot as a sign that it is newly cooked. If a food was cold a guest has to deal respectfully with this situation, he always expresses this emotion by saying the proverb 'The dish is hotter than soup' /ālmā ‘wn āḥr mn ālšwrbh/.

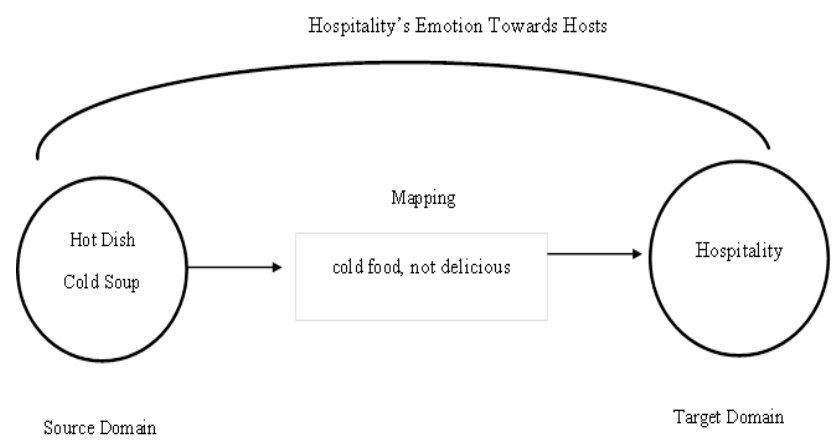

Figure 3.22 Image Schema of the Proverb "Hotter than Soup."

A speaker's knowledge appears through his experiences of two domains, one is 'the dish' /ālmā' wn/ being warmer than a second domain 'soup'/ālšwrbh/. 'Soup' /ālšwrbh/ has features of cold food less than the container 'the dish' /ālmā'wn/. To express that the food is not delicious, a speaker conceptualises his/her understanding of the abstract domain of emotion towards hosts whether it is positive or negative by linking it to the more concrete domain of hot dish.

\subsection{Corruption is Hot}

This proverb 'I didn't ask you to burn it but to let it be roasted' /māktlk āḥrkh' bs hllyhā tstwy/ is used to express a person who is careless and dose not be wise to deal with attitudes, and he/she always accepts opinions without thinking.

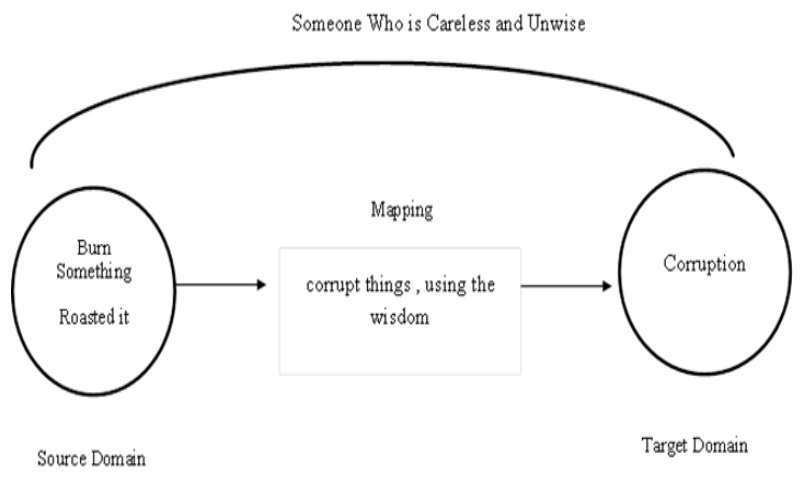

Figure 3.23 Image Schema of the Proverb "Not to Burn but Roast."

The phrase 'to burn it' corresponds to the fact that do not put in the right side whereas the phrase "let it be roasted' /hlyhā tstwy/ refers to the use of the wisdom to deal with attitudes. Therefore, there is a relation between the structure of entities of source domain 'burn' /yhrk/ and the speaker's understanding of the concept of corruption. The image schema of the source domain of burning things arises from the speaker bodily pre-experiences of someone who is carless in issuing opinions. A speaker, conceptualises his feeling of a target domain of corruption onto a set of mapping of concrete domain of burn things not to let it be roasted.

\subsection{Useless Man is Cold}

When someone is useless, he/she is described by experiencing this proverb 'He is not useful neither for hot nor for cold' /mā ynf' lā llḥmh wlā llbārdh/. The phrase 'He is not useful neither for hot' /mā ynf' lā llhmh/ refers to a high degree of temperature of a human body.

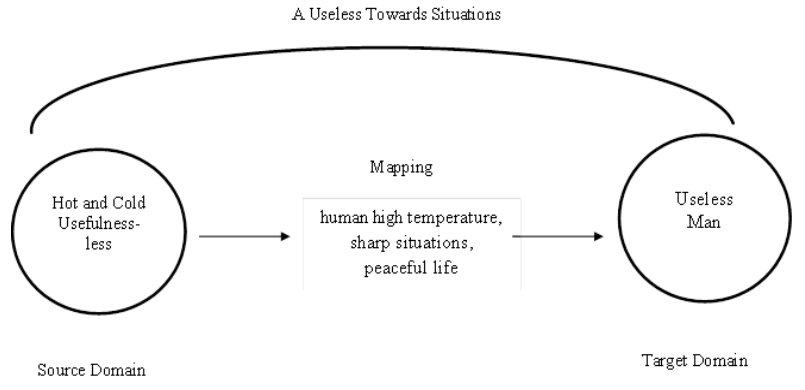

Figure 3.24 Image Schema of the Proverb "Useful Neither for Hot nor Cold." 
The phrase describes the sharp situations that a man may be exposed to. Whereas 'nor for cold' /wlā llbārdh/ describes a normal and peaceful life. The structure of the two domains corresponds the characteristics of a man who has no benefit in his relation with others. Thus, a speaker conceptualises his attitude of a target domain of useless man onto mapping of the more concrete domains of hot and cold for man being useless.

\subsection{Earning is Cold}

When someone earns money or get something without any effort, he is described by experiencing this proverb 'On comfortable coldness' /'lbārd ālmstryḥ/.

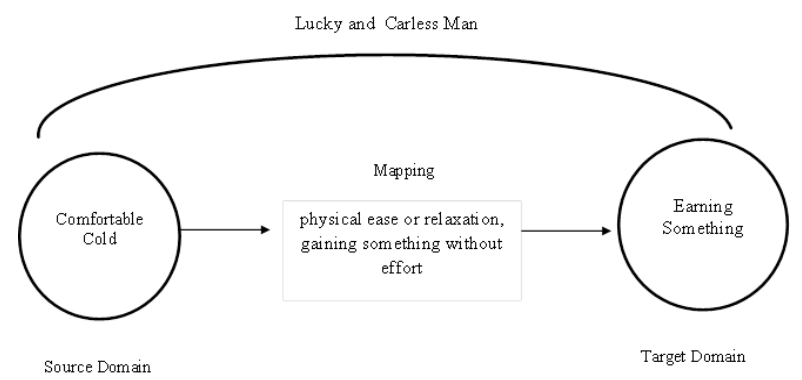

Figure 3.25 Image Schema of the Proverb "On Comfortable Coldness."

The image schema appears from the pre-conceptual bodily experience of cold being a physical ease or relaxation to conceptualise the abstract concept of gaining something without an effort. Hence, the entities of comfortable cold, like ease, relaxation, stillness...etc. correspond systematically to the person who is lucky, carless, etc. to gain something. In this case, a speaker, then conceptualises his abstract domain attitude towards a person who does not make an effort for earning something onto a set of mapping of the more concrete domain of comfortable cold.

\section{Conclusion}

In this study, the researchers tried to explore the way speakers in Iraqi community conceptualise the abstract domains of emotions and attitudes...etc. The study focused on the idiomatic and proverbial expressions, specifically southern dialect language.

The conceptual metaphor of Cold domain is used to conceptualise the bad habits of some people. A speaker conceptualises his understanding of some emotions and attitudes towards others, like the idiocy of someone, cheating others, betraying others, underestimating grace, a man who is careless toward others, a person who does not feel sexual prowess towards his/her wife, a person who gain something without any effort and a person who is not useful to do something.
Cold domain is also used to conceptualise some good habits of people, such as resolve problems, a person who enjoy composure in dealing with problems, feel satisfying a person who has an ability to make other calming. On the other hand, the conceptual metaphor of Hot domain is used to conceptualise the more intensive of emotions and attitudes, like a person's vitality, exploiting opportunities, waiting others, negatively changing facts, hesitation of doing something, self-sacrifice, feeling angry and nervous, lucky, fear of death, a careless man and good morals. The study also concluded that the sharp emotions, feelings and attitudes that are understood from the conceptualisation of $\mathrm{Hot}$ and Cold conceptual metaphors, are experienced from the more concrete domains of hard things, such as iron, cinder, ice, blood, pepper, grave, ice and pig blood.

Finally, the study showed that the bad habits that are understood from the experiences the cold things, such as 'Saqa back' /ṭyz ālsqh/, the bottom of 'Alhab'/ ālḥb/ whereas some good habits are understood from the experiences of cold your legs /wbrd rğlyk /, lover's heart / klb āl' āšk/, cold water /māy bard/, tear /āldm 'h/ and candle /ālšm ' $\mathrm{h} /$.

\section{Acknowledgment}

The researchers would like to express their great gratitude and thanks to Mr. Falah Hussein Al-Sarri M.A. for his efforts in translation and interpretation of the research data.

\section{References}

Akuno, L., Oloo, P. A., \& Magonya, A. L. (2018). The Object of Love is Food conceptual metaphor in selected Dholuo Benga music of 1970s and 2000s. Journal of Linguistics and Literature Studies, 6(1), 40-46.

Croft, W., \& Cruse, D. A. (2004). Cognitive linguistics. Cambridge University Press.

Derin, T., Deliani, S., Fauziah, N., Afifah, N., \& Hamuddin, B. (2019). Indonesians' Tendency to Refer Abbreviation as Acronym: Types of Abbreviation as Word Formation Process. Globish: An English-Indonesian Journal for English, Education, and Culture, 8(2). http://dx.doi.org/10.31000/globish.v8i2.1654

Ehineni, T. (2018). From conceptual metaphors to cultural metaphors: Metaphorical language in Yoruba proverbs and praise poems. Language Matters, 48(3), 130-144.

Evans, V,. \& Green, M. (2006). Cognitive linguistics: An introduction. Edinburgh University Press. 
Ferrando, I. N. (2017). Conceptual metaphor types in oncology: Cognitive and communicative functions. lbérica: Revista de la Asociacióin Europea de Lenguas para Fines Especificos (AELEF), 34, 163-186.

Forceville, C. (2019). Developments in multimodal metaphor studies: A response to Górska, Coëgnarts, Porto \& Romano, and Muelas-Gil. Current Approaches to Metaphor analysis in Discourse, 367, 378.

Gao, L. (2016). A comparative study of conceptual metaphors in English and Chinese economic news headlines. Creative Education, 7(17), 2629.

Geeraerts, D. (Ed). (2006). Cognitive linguistics: Basic readings. (Vol.34). Walter de Gruyter.

Geeraerts, D. \& Cuyckens, H. (2007). The Oxford handbook of cognitive linguistics. Oxford University Press.

Johnson, M. (1987). The body in the mind: The bodily basis of meaning, imagination, and reason. University of Chicago Press.

Kövecses, Z. (2000). Metaphor and emotion: Language, culture and body in human feelings. Cambridge University Press.

Kövecses, Z. (2005). Metaphor in culture: Universality and variation. Cambridge University Press.

Kövecses, Z. (2010). Metaphor: A practical introduction. Oxford University Press.

Kövecses, Z. (2015). Where metaphors come from: Reconsidering context in metaphor. Oxford University Press.

Kövecses, Z. (2016). Conceptual metaphor theory. In The Routledge Handbook of Metaphor and Language (pp.31-45). Routledge.

Kövecses, Z. (2017). The interplay between metaphor and culture. Zooming In: Micro-Scale Perspectives on Cognition, Translation and Cross-Cultural Communication, 18, 7-18.

Kövecses, Z. (2017). Levels of metaphor. Cognitive Linguistics, 28(2), 321-347.

Kövecses, Z. (2018). Metaphor in media language and cognition: A perspective from conceptual metaphor theory: Lege Artis, 3(1), 124-141.

Kövecses, Z., Ambrus, L., Hegedüs, D., Imai, R., \& Sobczak, A. (2019). The lexical vs. the corpusbased method in the study of metaphors. Metaphor and Metonymy in the Digital Age:
Theory and methods for building repositories of figurative language, 8.

Lakoff, G. (1993). The contemporary theory of metaphor. Cambridge University Press, p 202251.

Lakoff, G., \& Johnson, M. (1980). Metaphor we live by. The University of Chicago Press.

Landau, M. J. (2017). Using metaphor to find meaning in life. Review of General Psychology, 22(1), 6272.

Landau, M. J., Zhong, C. B., \& Swanson, T. J. (2018). Conceptual metaphors shape consumer psychology. Consumer Psychology Review, 1(1), 54-71.

Littlemore, J., \& Taylor, J. R. (2014). The Bloomsbury companion of cognitive linguistics. Bloomsbury Publishing.

Massey, G., \& Ehrensberger-Dow, M. (2017). Translating conceptual metaphor: The processes managing interlingual asymmetry. Research in Language, 15(2), 173-189.

Polova, O. (2020). Religious metaphors in public speeches in Turkish politicians. Journal of History Culture and Art Research, 9(1), 407422.

Roodt, V. (2019). Violence as metaphor. In Violence and Meaning. (pp.3-26). Palgrave Mcmillan.

Rasse, C., Onyska, A., \& Citron, F. M. (2020). Conceptual metaphors in poetry interpretation: A psycholinguistic approach. Language and Cognition, 12(2), 310-342.

Wisnita , A. E. (2019). Metaphor and Simile in English Context: Do They Know the Differences?. REiLA: Journal of Research and Innovation in Language, 1(2), 55-60. https://doi.org/10.31849/reila.v1i2.3066

Zibin, A. (2016). The Comprehension of metaphorical expressions by Jordanian EFL learners. Sage Open, 6(2), 1-15. 